\title{
AMENDMENTS
}

\section{Publisher Correction: Electronic structure of the parent compound of superconducting infinite-layer nickelates}

M. Hepting (D), D. LiD, C. J. Jia DD, H. Lu, E. Paris, Y. Tseng, X. Feng, M. Osada, E. Been, Y. Hikita, Y.-D. Chuang, Z. Hussain, K. J. Zhou (D, A. Nag, M. Garcia-Fernandez, M. Rossi (D), H. Y. Huang, D. J. Huang, Z. X. Shen (D) T. Schmitt, H. Y. Hwang,

B. Moritz, J. Zaanen, T. P. Devereaux and W. S. Lee (iD)

Correction to: Nature Materials https://doi.org/10.1038/s41563-019-0585-z, published online 20 January 2020.

In the version of this Letter originally published, the last term of the equation for $\varepsilon_{\mathrm{k}}^{\mathrm{R}}$ in the Methods incorrectly read $8 \mathrm{t}_{[2,1,1]}^{\mathrm{R}}\left[\cos \left(2 \mathrm{k}_{\mathrm{x}}\right)+\cos \left(\mathrm{k}_{\mathrm{y}}\right) \cos \left(\mathrm{k}_{\mathrm{x}}\right) \cos \left(2 \mathrm{k}_{\mathrm{y}}\right)\right] \cos \left(\mathrm{k}_{\mathrm{z}}\right)$; it should have read $8 \mathrm{t}_{[2,1,1]}^{\mathrm{R}}\left[\cos \left(2 \mathrm{k}_{\mathrm{x}}\right) \cos \left(\mathrm{k}_{\mathrm{y}}\right)+\cos \left(\mathrm{k}_{\mathrm{x}}\right) \cos \left(2 \mathrm{k}_{\mathrm{y}}\right)\right] \cos \left(\mathrm{k}_{\mathrm{z}}\right)$. This has now been corrected in the online versions of this Letter.

Published online: 13 July 2020

https://doi.org/10.1038/s41563-020-0761-1

๑) The Author(s), under exclusive licence to Springer Nature Limited 2020

\section{Author Correction: Evidence of higher-order topology in multilayer $\mathrm{WTe}_{2}$ from Josephson coupling through anisotropic hinge states}

Yong-Bin Choi, Yingming Xie DD, Chui-Zhen Chen, Jinho Park, Su-Beom Song, Jiho Yoon, B. J. Kim, Takashi Taniguchi, Kenji Watanabe (D), Jonghwan Kim, Kin Chung Fong (D), Mazhar N. Ali (D), Kam Tuen Law iD and Gil-Ho Lee (D)

Correction to: Nature Materials https://doi.org/10.1038/s41563-020-0721-9, published online 6 July 2020.

In the version of this Article originally published, the following sentence was missing from the end of the Acknowledgements: 'M.N.A. acknowledges support from the Alexander von Humboldt Foundation's Sofia Kovalevskaja Award and the BMBF MINERVA ARCHES Award. This has now been corrected in all versions of this Article.

Published online: 17 July 2020

https://doi.org/10.1038/s41563-020-0762-0

(c) The Author(s), under exclusive licence to Springer Nature Limited 2020

\section{Author Correction: Electrical switching in a magnetically intercalated transition metal dichalcogenide}

\author{
Nityan L. Nair, Eran Maniv, Caolan John, Spencer Doyle, J. Orenstein and James G. Analytis (D)
}

Correction to: Nature Materials https://doi.org/10.1038/s41563-019-0518-x, published online 4 November 2019.

In the version of this Letter originally published, the Supplementary Information incorrectly referred to Fe ${ }_{0.35} \mathrm{NbS}_{2} \mathrm{crystals}$ throughout; it should have referred to $\mathrm{Fe}_{0.33} \mathrm{NbS}_{2}$ crystals. Also, the following sentence should not have been included in the Supplementary Information so has been deleted: 'The switching is of approximately the same amplitude as the device shown in the main text.' Finally, in the caption of Supplementary Fig. 8, the current density was incorrectly given as $8.8 \times 10^{4} \mathrm{~A} / \mathrm{cm}^{2}$; it should have been $7.1 \times 10^{4} \mathrm{~A} / \mathrm{cm}^{2}$. The Supplementary Information has now been replaced to include these changes. 